Gerald P. Marquette MD FRCSC, *

Thomas Mechas MD FRCSC,*

Jean Charest MD FRCPC, $\ddagger$ Evelyne Rey MD FRCPC $†$

\title{
Epidural anaesthesia for elective Caesarean section does not influence fetal umbilical artery blood flow indices
}

This prospective study was.completed to determine the influence of epidural anaesthesia on the fetoplacental circulation of normal subjects. Thirty-seven normal pregnant patients at term, undergoing elective Caesarean section, had Doppler measurements of the fetal umbilical artery blood flow velocity before and after epidural anaesthesia using lidocaine $2 \%$ without epinephrine. There were no differences in systolic/diastolic, resistance or pulsality indices following epidural anaesthesia. These results suggest that this technique has no adverse effect on fetoplacental circulation in normal non-labouring subjects.

Cette étude prospective a pour but de déterminer linfluence de l'anesthésie épidurale sur la circulation foeto-placentaire dans le contexte d'une grossesse normale. Des indices de vélocité du flot de l'artère ombilicale foetale ont été mesurés par Doppler chez trente-sept patientes gravides à terme, sans complications, programmées pour une césarienne élective, avant et après une anesthésie épidurale utilisant la lidocaüne $2 \%$ sans épinéphrine. Les indices de rapport systole/diastole, de résistance et de pulsatilité sont demeurés inchangés après l'induction de l'anesthésie épidurale. Ces constatations suggèrent que l'anes-

\section{Key words}

ANAESTHESIA: obstetric;

ANAESTHESIA TECHNIQUE: epidural;

BLOOD: flow velocity, umbilical artery;

MEASUREMENT TECHNIQUES: Doppler, continuous;

PLACENTA: circulation.

From the Department of Obstetrics and Gynaecology, Division of Maternal and Foetal Medicine," Division of Obstetrical Medicine $\nmid$ and Department of Anaesthesia, $\ddagger$ Sainte-Justine Hospital, University of Montreal, Montreal (Quebec), Canada.

Address correspondence to: Dr. Gerald P. Marquette, Dept. of Obstetrics and Gynaecology, Sainte-Justine Hospital, 3175 Cote Ste-Catherine Road, Montreal (Quebec), Canada H3T $1 \mathrm{C5}$.

Accepted for publication 18th July, 1994. thésie épidurale n'a pas dinfluence sur la circulation foetoplacentaire chez des patientes enceintes normales à terme qui ne sont pas en travail.

Epidural anaesthesia.is an established method of anaesthesia for Caesarean section. Since the introduction of epidural anaesthesia, the risks of maternal aspiration and neonatal drug depression have been reduced drastically. ${ }^{\prime}$ Furthermore, it has been possible for the mother and father to witness the birth of their child. ${ }^{2}$ However, fetoplacental circulation may potentially be altered ${ }^{3}$ by maternal haemodynamic changes secondary to epidural anaesthesia, despite intravenous pre-load and adequate maternal positioning.

Fetal umbilical artery blood velocity indices (Figure) have been used to quantitate resistance to flow in the feto-placental circulation, especially in diastole. Normally, at term, diastolic flow in the fetal umbilical artery is elevated, thus permitting better circulation and exchange throughout the cardiac cycle at the level of the placenta. The systolic and diastolic flow pattern resembles that of an arterial-venous fistula. Different clinical situations have been associated with decreased, absent or reversed diastolic flow, representing worsening grades of fetal compromise.

Morrow et al. have studied the influence of epidural anaesthesia on systolic/diastolic ratio (S/D) of the fetal umbilical artery at term. ${ }^{4}$ Although no change in S/D ratio was found, the study was based on only 12 subjects, and lidocaine and epinephrine were used to achieve adequate anaesthesia. Baumann et al. ${ }^{5}$ demonstrated an increase in uteroplacental blood flow indices in 11 of 13 patients undergoing epidural anaesthesia using lidocaine with epinephrine at term. In this study, no change was seen in the umbilical artery circulation but the study was based on a small number of subjects undergoing Caesarean section for diverse indications. Other studies used 


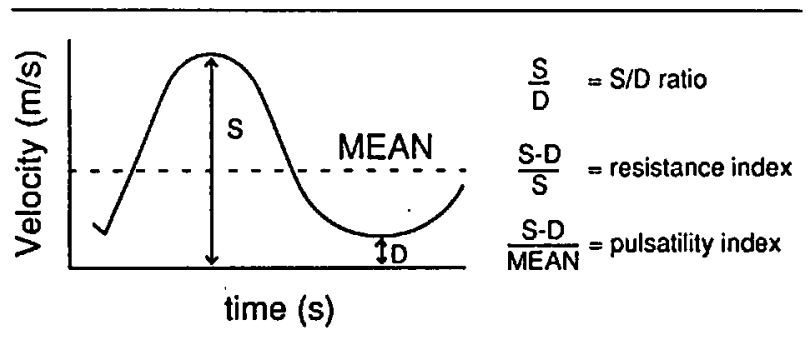

$\begin{array}{ll}\pi / s: \text { moters / second } & \text { S: maximum systolic velocity } \\ \text { time (s): time in seconds } & \text { D: minimum diastolic velocity }\end{array}$

MEAN: moan velocily

FIGURE The schematic arterial waveform with different blood flow velocity indices.

different anaesthetics in labouring patients. It is the goal of this study to evaluate the influence of epidural anaesthesia using only lidocaine on fetal umbilical artery flow prior to elective Caesarean section in healthy pregnancies at term using non-invasive Doppler methods.

\section{Methods}

The following study was approved by our institutional Research and Ethics Committee. After written informed consent, 37 non-labouring patients scheduled for elective Caesarean section at 38 or 39 wk were included in this prospective study. All were uncomplicated singleton gestations, i.e, without diabetes, anaemia, hypertension, intra-uterine growth retardation, insufficient anaesthesia or known fetal anomalies. Prior to anaesthesia, all patients were given a $30 \mathrm{ml}$ solution of sodium citrate, 3.0 $\mathbf{M}$ po. The patients were placed in the supine position with a left lateral tilt. Using a Multigon 500 continuous wave Doppler, the fetal umbilical artery was identified using its characteristic flow velocity pattern. ${ }^{6}$ As measurements of flow velocity are dependent on the angle at which reflected signals are obtained, it was essential to use ratios of measurements to eliminate the possible error related to the angle. Flow velocity indices (Figure) are angle-independent and, therefore, have been used clinically to outline fetal umbilical circulation for over a decade. The following indices (Figure) of umbilical artery blood flow velocity were measured prior to placement of the epidural catheter: systolic/diastolic (S/D) ratio, pulsatility and resistance indices. Using this technique, an average variation of $6 \%$ could be anticipated. ${ }^{6}$ The indices were all computed simultaneously, using the software package accompanying the Doppler instrument. Reported values represent the mean of three consecutive measurements of three cardiac cycles each.

Epidural anaesthesia was then performed using the same technique for all patients. After an intravascular preload of one to two litres Ringer's lactate with the pa-
TABLE Fetal umbilical artery flow velocity indices before and after epidural anaesthesia for elective Caesarean sections at term as experienoed as means \pm standard deviation

\begin{tabular}{llll}
\hline Indices $n=37$ & Before epidural & After epidural & \\
\hline S/D & $2.26 \pm 0.24$ & $2.26 \pm 0.3$ & NS \\
Resistance index & $0.57 \pm 0.04$ & $0.57 \pm 0.07$ & NS \\
Pulsatility index & $0.83 \pm 0.10$ & $0.83 \pm 0.16$ & NS \\
\hline
\end{tabular}

NS: Not significant.

tiènt in the sitting position, an epidural catheter was placed in the $\mathrm{L}_{2}-\mathrm{L}_{3}$, or $\mathrm{L}_{3}-\mathrm{L}_{4}$ lumbar intervertebral space. Immediately after, the patient was placed in the supine position with a left lateral tilt. Incremental doses of lidocaine $2 \%$ without epinephrine ranging from 360 $\mathrm{mg}$ to $520 \mathrm{mg}$ were injected to produce the desired level $\left(T_{4}\right)$ of anaesthesia for surgery. Vital signs were monitored every two minutes during induction of anaesthesia using an automated blood pressure monitor, continuous ECG and pulse oximeter. As soon as the level was verified at $T_{4}$ using needle prick and/or ice, the Doppler measurements were repeated. A paired $t$ test was used to compare measurements before and after epidural anaesthesia. A level of $P<0.05$ was considered significant.

\section{Results}

The mean maternal age was $31.5 \pm 3 \mathrm{yr}(\mu \pm \mathrm{SD})$. The gestational age at delivery was $38.9 \pm 0.9 \mathrm{wk}$ and the mean birthweight was $3291 \pm 229 \mathrm{~g}$. There were no statistical or clinical differences in indices before and after epidural anaesthesia (Table). The median interval between placing the catheter and achieving the level of anaesthesia required for surgery was 22 minutes, ranging from 17 to 36 mins. The median interval between Doppler measurements was 29 mins, with a range of 23 to 44 mins. Five patients required five to ten milligrams ephedrine to correct hypotension of no more than three minutes duration before surgery. This was diagnosed after a decrease in systolic of approximately $25 \mathrm{~mm} \mathrm{Hg}$ or diastolic of $15 \mathrm{mmHg}$ in maternal blood pressure readings. None of these hypotensive patients had levels of anaesthesia above $T_{4}$. Two of these patients experienced palpitations and weakness. In these two, Doppler measurements were taken during the hypotensive period, and no difference in indices was noted from the measurements prior to anaesthesia. All maternal and neonatal outcomes were normal. There were no complications related to epidural anaesthesia.

\section{Discussion}

The fetoplacental unit is a low resistance, high-flow vascular system. Increases in resistance in this compartment are associated with decreased umbilical artery flow, and 
eventually decreased fetal oxygenation. This increase in resistance is detectable as an increase in the three Doppler indices we have evaluated. Marx et al. ${ }^{7}$ have shown that, in labour, epidural anaesthesia was associated with a decrease in S/D ratio of the fetal umbilical artery flow velocity in healthy parturients. This is compatible with a decrease in vascular resistance in the fetoplacental unit. They suggested that this advantageous result was secondary to a decrease in maternal adrenergic response associated with pain relief. However, using a different technique, Jouppila et al. ${ }^{8}$ have shown a reduction in placental blood flow in the same circumstances in a small group of patients. This may be attributable to different medications ${ }^{9,10}$ and their concentrations in the induction of epidural anaesthesia in the two studies. Furthermore, in the later study, the subjects were noted to have severe hypotension. In another small series, Giles et al." demonstrated a decrease in the S/D ratio after induction of epidural anaesthesia with bupivicaine without epinephrine in normal patients undergoing elective Caesarean section. Although this may be considered a beneficial effect, this may also be secondary to the cardiac depression caused by this agent. ${ }^{12}$

In the clinical situation investigated in our study, pain was not a cofactor since epidural anaesthesia was used for elective Caesarean section at term. Therefore, unlike the study of Marx et al., ${ }^{7}$ we would not expect to observe a variation in placental resistance. Our findings may also differ from those of Giles $e t$ al., ${ }^{11}$ because of the use of lidocaine rather than bupivicaine. ${ }^{12}$ Bupivicaine has been shown to have up to 20 times the negative inotropic effect of lidocaine and, therefore, has been considered a cardiac depressive agent.

After general anaesthesia, Jouppila et al. ${ }^{13}$ have demonstrated a reduction of placental intervillous flow. Tracheal intubation stimulates a positive-pressure response ${ }^{14}$ that decreases uterine blood flow during elective Caesarean section at term. Circulating levels of epinephrine correlate well with these pressure responses. ${ }^{15,16}$ Therefore, these findings may favour use of epidural anaesthesia in these circumstances.

A continuous wave Doppler was used throughout this study. Recognition of the umbilical artery was easily performed. The indices reported were the mean of three measurements of three cycles each. This was to lower variations in test results. Only two experienced authors completed all the measurements. This was accomplished in an effort to decrease variation in Doppler measurement. Brar et al. ${ }^{17}$ demonstrated that continuous-wave Doppler measurements produced similar results as pulsed Doppler measurements of the umbilical artery flow velocity. Therefore, this study would not have benefited from the addition of pulse Doppler indices.
When the uterus is not contracting, uteroplacental blood flow is not autoregulated. ${ }^{18}$ There is almost maximum vasodilatation of the arterioles feeding the placental bed. Therefore, a considerable decrease in maternal blood pressure could affect maternal supply to the placenta. The reported incidence of hypotension following epidural anaesthesia will vary according to the definition of hypotension, the type of prophylaxis, the extent of epidural block and the frequency of blood pressure monitoring. ${ }^{3}$ Nonetheless, hypotension following adequate preload and positioning of the mother is not frequent $(6.7 \%) .{ }^{19} \mathrm{Con}-$ sequently, in our study, hypotension was not anticipated and, therefore, this was not used as an outcome measure. The two patients that were symptomatic were evaluated at the time of treatment with ephedrine. No difference in flow indices was observed at that time as compared to the protocol measurements. Although it would have been useful to have continuous monitoring of indices throughout the interval between the first and second measurements, this would have been technically difficult. Firstly, it would be difficult to achieve during the placement of the epidural catheter with the patient in the sitting position. Secondly, subjecting patients throughout the induction of anaesthesia would have increased this exposure and could also have decreased enrolment in our study.

This study included 37 patients. There were no statistical or clinical differences in flow velocity indices before and after epidural anaesthesia for elective Caesarean section at term. Veille et al. ${ }^{20}$ used 2-chloroprocaine with epinephrine to achieve the desired level of anaesthesia. Our study reviewed the influence of lidocaine without epinephrine on umbilical flow indices, which has not previously been reported. Similar results were reported by Morrow et al. ${ }^{4}$ when using lidocaine with epinephrine. Baumann et al. ${ }^{5}$ have shown an increase in indices in the uteroplacental circulation, but not in the umbilical blood flow, using lidocaine $2 \%$ with epinephrine. Our study has twice the number of subjects as that of Veille, ${ }^{20}$ Morrow $^{4}$ and Baumann, ${ }^{5}$ who had similar findings. Therefore, increasing enrolment would not be likely to change the results of our study.

In our study, the use of Doppler ultrasound did not demonstrate any effect of lidocaine $2 \%$ without epinephrine during epidural anaesthesia on the fetal umbilical artery flow velocities.

\section{References}

1 Shnider SM, Levinson G. Anesthesia for cesarean section. In: Shnider SM, Levinson G (Eds.). Anesthesia for Obstetrics, 2nd ed. Baltimore: Williams \& Wilkins, 1987; 160.

2 Moir DD. Extradural analgesia for Caesarean section (Editorial). Br J Anaesth 1979; 51: 79-80.

3 Brizgys RV, Dailey PA, Shnider SM, Kotelko DM, Levin- 
son $G$. The incidence and neonatal effects of maternal hypotension during epidural anesthesia for cesarean section. Anesthesiology 1987; 67: 782-6.

4 Morrow RJ, Rolbin SH, Ritchie JWK, Haley S. Epidural anaesthesia and blood flow velocity in mother and fetus.

Can J Anaesth 1989; 36: 519-22.

5 Baumann H, Alon E, Atanassoff P, Pasch T, Huch A, $H u g h \quad R$. Effect of epidural anesthesia for cesarean delivery on maternal femoral arterial and venous, uteroplacental, and umbilical blood flow velocities and waveforms. Obstet Gynecol 1990; 75: 194-8.

6 Schulman H, Fleischer A, Stern W, Farmakides G, Jagani $N$, Blattner $P$. Umbilical velocity wave ratios in human pregnancy. Am J Obstet Gynecol 1984; 148: 985-90.

7 Marx GF, Patel S, Berman JA, Farmakides G, Schulman $H$. Umbilical blood flow velocity waveforms in different maternal positions and with epidural analgesia. Obstet Gynecol 1986; 68: 61-4.

8 Jouppila R, Jouppila P, Kuikka J, Hollmén A. Placental blood flow during Caesarean section under lumbar extradural analgesia. Br J Anaesth 1978; 50: 275-9.

9 Tucker GT, Mather LE. Properties, absorption, and disposition of local anesthetic agents. In: Cousins MJ, Bridenbaugh PO (Eds.). Neural Blockade in Clinical Anesthesia and Management of Pain, 2nd ed. Philadelphia: JB Lippincott, 1988; 69.

10 Block $A$, Covino BG. Effects of local anesthetic agents on cardiac conduction and contractility. Reg Anesth 1981; 6: 55-61.

11 Giles WB, Lah FX, Trudinger BJ. The effect of epidural anaesthesia for caesarean section on maternal uterine and fetal umbilical artery blood flow velocity waveforms. $\mathrm{Br} \mathbf{J}$ Obstet Gynaecol 1987; 94: 55-9.

12 Clarkson CW, Hondeghen LM. Mechanism for bupivacaine depression of cardiac conduction: fast block of sodium channels during the action potential with slow recovery from block during diastole. Anesthesiology 1985; 62: 396-405.

13 Jouppila P, Kuikka J, Jouppila R, Hollmén A. Effect of induction of general anesthesia for cesarean section on invervillous blood flow. Acta Obstet Gynecol Scand 1979; 58: 249-53.

14 Fox EJ, Sklar GS, Hill CH, Villanueva $R$, King $B D$. Complications related to the pressor response to endotracheal intubation. Anesthesiology 1977; 47: 524-5.

15 Lederman RP, McCann DS, Work B Jr, Huber MJ. Endogenous plasma epinephrine and norepinephrine in last-trimester pregnancy and labor. Am J Obstet Gynecol 1977; 129: 5-8.

16 Shnider SM, Abboud TK, Artal R, Henriksen EH, Stefani SJ, Levinson $G$. Maternal catecholamines decrease during labor after lumbar epidural anesthesia. Am J Obstet Gynecol 1983; 147: 13-5.
17 Brar HS, Medearis AL, DeVore GR, Platt LD. A comparative study of fetal umbilical velocimetry with continuousand pulse-wave Doppler ultrasonography in high-risk pregnancies: relationship to outcome. Am J Obstet Gynecol 1989; 160: 375-8.

18 Battaglia FC, Meschia G. An Introduction to Fetal Physiology. New York: Academic Press, 1986; 218.

19 Lewis $M$, Thomas $P$, Wilkes $R G$. Hypotension during epidural analgesia for Caesarean section. Anaesthesia 1983; 38: 250-3.

20 Veille JC, Youngstrom P, Kanaan C, Wilson B. Human umbilical artery flow velocity waveforms before and after regional anesthesia for cesarean section. Obstet Gynecol 1988; 72: 890-3. 